\title{
Life Cycle of Public Transportation Companies of DR Congo -A Diachronic and Synchronic Analysis
}

\author{
Corneille Luboya Tshiunza ${ }^{1,2^{*}}$, Huguette Sifa Bura ${ }^{3}$, Chance Kibembo Kibuka ${ }^{3}$ \\ ${ }^{1}$ School of Education, Central China Normal University, Wuhan, China \\ ${ }^{2}$ School of Psychology and Educational Sciences, National Pedagogical University, Kinshasa, Congo \\ ${ }^{3}$ School of Economics and Business Administration, Central China Normal University, Wuhan, China \\ Email: *corneilleluboya@outlook.fr
}

How to cite this paper: Luboya, T.C., Bura, S.H. and Kibembo, K.C. (2018) Life Cycle of Public Transportation Companies of DR Congo-A Diachronic and Synchronic Analysis. Open Journal of Social Sciences, 6, 302-318.

https://doi.org/10.4236/jss.2018.65022

Received: April 23, 2018

Accepted: May 28, 2018

Published: May 31, 2018

Copyright $\odot 2018$ by authors and Scientific Research Publishing Inc. This work is licensed under the Creative Commons Attribution International License (CC BY 4.0).

http://creativecommons.org/licenses/by/4.0/

\begin{abstract}
In most of developing countries, the public transportation remains the challenges for most of the population. This inherent situation is observed in Democratic Republic of the Congo (DRC) where the demand of public transportation exceeds the supply. It has been found that public transportation companies are created, but they eventually fall into bankruptcy. The causes can be of course diverse. The objective of this study is to trace and describe the life cycles of these transportation companies of DR Congo in the diachronic and synchronic perspective. Using the documentary analysis of secondary data and interviews, the findings provide a description of the life cycles of the DRC transportation companies according to their cycle duration, types and steps in the diachronic and synchronic perspective.
\end{abstract}

\section{Keywords}

Transportation Company, Public Transportation, Organization Failure, Life Cycle Model, Diachronic and Synchronic Analysis

\section{Introduction}

In some sectors in organizations, it has been observed for some decades on a global, continental, national, provincial or even in local environments that the live of companies follows a cycle. The normal course steps as described by the Life cycle theory are birth, growth, maturity, decline and finally death. Certain companies are able to renew or recommence in one form or another. On the other hand, some categories of companies, deemed dead-born or stillborn, are 
disappearing early. It is clear that companies have a considerable contribution to the promotion of the living conditions of the human community. Indeed, the Highly Industrialized States owe their emancipation stage, not only, to a large extent to wealth-creating companies, but also to a strong economy and an adequate employment-creation policy. It was noted that about the global statistics of business failures every year, nearly 55,000 companies and 250,000 employees are affected by the failure. This remains a complex phenomenon which the analysis is limited, however, to either purely quantitative aspects or to the only legal framework (Luboya, 2011) [1].

For the past three decades, it has been bitterly noted that transportation companies are born in Democratic Republic of the Congo (DRC), but most of them are not able to live as long as possible and some do not reach a decade. This situation is more unsettling in a country where the demand for means of public transportation far exceeds the supply and is only increasing. Moreover, the failure of these companies is generally not necessarily brutal, but it is the result of a decreasing process over several years with the obviously diverse causes. In other words, the large enterprises of the DRC urban transportation have difficulties not only to satisfy the demand (Mwanza, 1997) [2] but also and above all to manage their life cycle in other to avoid their failure. Thus, the aim of this study is to trace and identify the life cycles of these DRC public transportation enterprises in the diachronic and synchronic perspective. On this, the study applies to answer the following questions:

1) What is the life cycle evolution of public transportation companies in DR Congo in the diachronic perspective?

2) What and how are the life cycles of these public enterprises described according to duration, types and stages in a synchronic perspective?

\section{Theoretical Foundation}

Three sections are developed: 1) overview on public transportation in DR Congo; 2) overview on bankruptcy of organizations and 3) overview on life cycle model.

\subsection{Overview on Common Transportation in DR Congo}

The challenges of public transportation are among the socio-economic problems that DR Congo population facing. In the great cities, especially in the capital city of Kinshasa the public transportation is mainly provided by private people. The private companies do not always have vehicles in sufficient quantity and in good conditions.

Only one public transportation company (Transportation of Congo, TRANSCO) for whole country is unable to cover the high demand for transportation of DRC population. Indeed, the vastness of the city, the volume of the population, the structure and the state of the roads, the concentration in a single pole of almost all the services, the weakness and the ageing of the automobile cartage, etc., make transportation an ordeal for the population of Kinshasa. 
These transportation difficulties are relative in the different times of the day.

Some academic studies (Luboya, 2011; Kabambu, 2005; Mputu, 2005; Mutombo, 2008) [1] [3] [4] [5] are interested in public transportation issues in DR Congo. According to these studies, it comes to the following conclusions: 1) transportation has a considerable impact on the development of the DR Congo; 2) the labor force is moving for the following purposes: $35 \%$ business, $20 \%$ of workers and $20 \%$ for training (students) and $25 \%$ for other occupations; 3 ) the existence of a inadequation between supply and demand for transportation in the capital province of Kinshasa but also on the entire extent of the republic; 4) the majority (87\%) of the population waits for their transportation in the morning; 5) the majority of passengers (70\%) travels in bad conditions and 6) traffic jams and scrambles in $85 \%$ of cases are the usual conditions for passengers.

To better understand the current situation of transportation in Kinshasa, the study refers to the historical evolution of transportation of the city. The internationally accepted ratio provides for a bus per hundred inhabitants at most and the evolution remains catastrophic. In 1972, the OTCZ had a park of at least 200 buses for 1.5 million inhabitants, a ratio of one bus for more or less 188.8 for 189 inhabitants (Mwanza, 1997) [2]. At the moment when the entire capital even country has about 345 buses in which one bus has 100 seats (all the large public companies combined) and the demographics estimate the population of Kinshasa to more than 8 million inhabitants, this ratio becomes upsetting: 231.884 for 232 inhabitants for a bus. The current state of transportation in Kinshasa, therefore, gives a glaring gap between supply and demand for transportation (Luboya, 2011) [1].

\subsection{Overview on Bankruptcy of Organizations}

Bankruptcy and failure have points of divergence and convergence. To make the clear difference between these two concepts, Combrier and Blazy (1998) [6] postulate that the concept of failure procedure judgement should not be confused (the filing of a balance sheet of an company registered in the context of a judicial or legal procedure which does not necessarily resolve by liquidation or disappear) and the broader concept of cessation of economic activities of a company (total or full stop of economic activity of a company). The liquidation due to a failure represents only part of the process of dissolving the business (one step to bankruptcy), in the order of $20 \%$ but varying over time and sectors of activity.

The study states that the bankruptcy (total stoppage of business activity) is more serious than a simple cessation of payments, which is the failure because it can benefit from a continuation plan through judicial and financial adjustments. The bankruptcy is declared by the manager of a company and is pronounced by a judgment of the Court of First Instance at whose registry the confession must be made. However, the business failure is ascertained by the third parties when there is a deficit or a figure or the normal operations or productions of an enterprise. 
In this point, the study considers that the notions of failure and performance (or efficiency) are generally linked. Since there is no unanimously recognized definition of the concepts of performance and efficiency in the literature (Cameron, 1986) [7], the study has chosen to define these concepts according to the precepts of the strategic alignment life cycle model (Miller, 1992; Tushman et al, 1986) [8] [9].

Thus, some major common steps can be identified in the process of failure of any company: the origin of the failure, the onset and the deterioration of the symptoms of failure, the red switch of the blinkers and the potential bankruptcy of the company (Crutzen and Van Caillie, 2007) [10]. Nevertheless, some researchers such as Argenti (1976) [11], D’Aveni (1989) [12] and Laitinen (1991) [13] have shown that not all companies behave in the same way when they evolve in a failure process. The different types of failure trajectories can therefore be identified, in particular according to the origin of the failure or the intrinsic characteristics (age, sector of activity, size) of the company.

With regard to the sector of companies moving towards bankruptcy, Combier and Blazy (1998) [6] conclude that the bankruptcy statistics of the organizations show an increase each year the sectors most affected are transportation $(+11.1 \%)$, the real estate activities $(+8.9 \%)$ and accommodation $(+4.6 \%)$. However, the improvement should continue in agriculture $(-4 \%$ of failures) and in construction $(-1.1 \%)$.

In addition, several published studies and thousands of unpublished studies dealing with estimating the risk of a company's bankruptcy. Several models have been proposed. These models of the prediction of bankruptcies, based mainly on various statistical methods (Beaver, 1966; Zavgren, 1983; Van Wymeersch and Wolfs, 1996) [14] [15] [16] and other models are analyzing bankruptcy in the managerial aspects (Balcaen and Ooghe, 2006) [17]. These two perspectives limit the scope and generalization. A unifying conceptual framework is needed if the researchers are to continue to evolve, advance the literature on the prevention of business failures (Dimitras et al., 1996; Morris, 1997) [18] [19]. Thus, Crutzen and Van Caillie (2007) [20] have proposed a balanced unifying model and this model have been validated empirically by study of Luboya on 140 private schools experiencing failure (Luboya, 2018) [21]. The study focuses on the life cycle and uses model of diachronic and synchronic analysis.

\subsection{Overview on Life Cycle Model}

The live cycle term is used in evolution approach in order to describe the growth of an organization as one sequential period of punctual events of live time of company or industry (Hatch, 1997) [22]. Luboya (2018) [21] estimate that in one company or industry there are several types of live cycle: 1 ) the life cycle of material or products (output: goods or services) of organization; 2) the life cycle of human and social resources in frame work of management of human resources; 3) the life cycle of strategies of marketing and selling; and 4) the life cycle of au- 
tonomy management of company or industry (Luboya, 2018) [21]. Our study is focused on the last perspective of live cycle (v).

Thus, several models of life cycle were established. Among the study refer to the model of Hersey, Kenneth and Blanchard (1972) [23]; the model of Adizez and Ichak (1988) [24] (quoted by Luboya, 2014) and the model of Quinn and Cameron (1983) [25]. Frois (1997) [26] states that as human, each company has a life cycle, comprising stages of development, of which design, gestation, birth, growth, decline and death In the life cycle described by the economists, the birth corresponds to the launching of a company; youth with the growth and adolescence correspond to periods of expansion and turbulence of the company; the adult period and old age, correspond to a maturity of the company in an environment, followed by a decline, until death even the renewal (Luboya, 2018, Lakoff and Johnson, 1980, Luboya et al., 2017,) [21] [27] [28].

From this perspective, many studies suggest five phases of the life cycle of an Organization (Luboya, 2018) [21]. There is launching or birth or foundation, the Growth or youth, the Maturity or stabilization and Decline and death. Luboya et al., (2017) [28] stated from the point of view of the duration, the organization may live three categories of life cycle: the short-term cycle from zero to one year of life; the medium-term cycle from two to five years of life; and the long-term cycle more than five years of life. From stages perspectives, the organizations can live six steps: 1) the phase of birth, starting or launching; 2) the phase of growth or blooming 3) phase of maturity or stabilization; 4) the phase of decline or failure then; 5) death or disappearance and 6) the phase of renewal or rebirth. However, most of companies or industries lived the complete cycle; following by the industries which lived the still-born firms' cycle; the irregular and incomplete; the reincarnation cycle; and the premature-reincarnated cycle.

\section{Methodology}

\subsection{Research Design}

The study is part of the qualitative approach. It refers to the meanings, concepts, definitions, characteristics, metaphors, symbols and descriptions of documents produced by people (Berg, 2009) [29]. Qualitative data is essentially information about the world in the form of words (Punch, 2005) [30]. Qualitative research is based on constructivism. The constructivism emphasis the social phenomena are made by social actors. The main goal is to analyze the life cycles of DRC public transportation companies. The study made the interpretation of what the researchers have read, seen, heard and understood about the bankruptcies of these companies. These interpretations cannot be separated from their own context, history, context and prior understanding (Creswell, 2007) [31].

\subsection{Data Collection and Instruments}

The study uses mainly the documentary research. It is the set of steps for searching, identifying and finding documents related to a subject through the 
development of a research strategy (Pochet, Chevillotte and Noël, 2005; Bashwtitz, Antonia, De Ketele, De Godelet, 2010) [32] [33]. This documentary research takes place according to a number of stages of documentary analysis: definition of the topic and description of research thematic, search of documents, selection of documents, exploitation of information, synthesis of information, and return of information. As additional methods, the study also used the methods of observation and in-depth interviews with 18 people from the DRC Ministry of Transportation services who lived through the life cycles of the least three public transportation companies in the DRC. The term "interview" expresses the one-on-one conversation through a topic. This communication between two persons or more is implemented in the context in which the researcher acted in the role of the interviewer and the each of 18 participants played in the role of the interviewee. The researcher asks questions, the participant responds. The interviews involved a transfer of qualitative data from the agents of National Ministry of Transportation to researcher. The interviews are particularly useful for getting the story behind a participant's experiences. The interviewer can pursue in-depth information around the topic. Interviews may be useful as follow-up to certain respondents to questionnaires, for example, to further investigate their responses (McNamara, 1999) [34]. The study used the scheduled interview and semi-directive interview (Creswell, 2007; Chilisa and Preece, 2005) [31] [35].

\subsection{Data Analysis}

Kvale (1996) [36] stated that the interview as qualitative research method seeks to describe and the meanings of central themes in the life world of the participants. The main task of researcher was to understand the meaning of what the interviewees think through their personal opinions about their experience of life cycle of these companies. Analyzing the data collected through the interviews, the study used the analysis of content (Badin, 1993) [37]. Content analysis has resulted in qualitative analysis that does not exclude a quantitative interpretation. The simplest and most traditional processes consisted in organizing the contents in the themes and sub-themes, translating into frequencies or simply counting the elements of the analysis. These frequencies have been converted into percentages in order to measure the duration of phases and types of life cycle of the DRC transpiration companies.

The study also used the documentary analysis. It allowed the collection of secondary data. It made it easier for the researchers to access with lowest cost in their location because it is already assembled and prevented us from picking up the managers or former employers of these companies. Its historical value and usefulness in evaluating and comparing primary data collected through interviews with the 18 resource persons (Baumard et al., 2003) [38]. The use of various official documents made it possible to complete the data collected by the interviews. It is said that the study analyses and exploits the reports and docu- 
ments of the bankrupt DRC public transportation companies in order to describe the diachronic aspect of life cycles of the public transportation companies.

\section{Results}

The study presents the results according to research questions as follows:

\subsection{Life Cycle of Public Transportation Companies in DR Congo According to the Diachronic Perspective}

Public transport in the DRC dates back to the years 40 (Table 1). At that time, the extra-customary center of Leopoldville (Kinshasa actually) had fewer than 500,000 inhabitants, of whom 45,000 autochthonous workers accounted for 15 percent of the total population. The distance that workers had to walk between their home and work was an average of more than $3 \mathrm{~km}$. This working population that travelled by bicycle was less than 10\%. It was only in 1947 that Mrs Pipins, a Greek subject, for the first time put into operation the largest utility vehicle for public transportation. This feat was successful and facilitated the movement of the population.

Following this experience, the creation of the public Transportation Company in Leopoldville (TCL) was achieved. Officially, the motivations behind the creation of TCL were to: 1) liberate workers from the obligation to walk the enormous distance between their homes and their place of business; 2) to release employers from concern that their cause is the assignment of important rolling stock to transportation their personnel (1955). Then the management problems began with the initiative of DRC governance to nationalize all companies in 1976.

In 1968, in order to meet the increasing needs of common transportation, a second company was created (Mwanza, 1997) [2]. The Company of Transportation of Kinshasa (STK) was created on 23 September 1968 and brought into circulation 30-bus cartage. The STK had added its buses in 1969 by a second cartage of 40 new buses. At this time, the company operates 19 lines and has opened agencies within the several cities of DRC provinces (Kisangani, Mbandaka and Lubumbashi) but very quickly, towards the year 1972, the STK enters a period of decline and in 1979, it operates only two lines. It will disappear completely in 1982 (Mwanza, 1997). This initiative will contribute, starting from 1973, at the time of the shortness of the Zaire transportation Office (OTZ, formerly TCL), to the emergence of a large number of large-scale artisanal sector enterprises (Dilandos, Auto Zaïre service, Vivi...).

These companies used "Fula-Fula" (one kind of vehicle) and the proliferation of small-scale operators with a maximum of one or two "combi" vehicles, "Hiace" and other bus taxis. Also in the same year are the "Kimalu-Malu", that is to say the vans, tarpaulin, very fast and specialized in the exploitation of short distances. All these companies are not able to question the presence of companies of the artisanal sector, which evolved in such a way that in 1956 saw the day 
the transportation systems by the private taxi-bus.

Currently, some forms of means of transportation tend to disappear from traffic, but very surely, so that since 1988, the "Kimalu-Malu" and "Fula-Fula" have disappeared from the urban traffic. As for the "combi", their number decreases progressively. Most of these means of transportation are operated by the private for the transportation of small distances. The "Kimalu-Malu" and "Fula-Fula" have disappeared since the appearance of two companies TRANZAM and CITY-TRAIN.

Only private taxis are in competition and are still struggling to operate the urban network to the point of constituting the most important common transportation offer across the country. Alongside these creations, companies specializing in the collection of civil servants, workers, pupils and students and in the collection of businesses have multiplied. A new public company was launched; it concerns Transport of Congo (TRANSCO).

Among the main public transportation companies (Table 1), the study explains:

1) Transportation Company of Leopoldville, (TCL) was created in 1947 and management problems began in 1971. This company fell bankrupt in 1976.

2) Company of Transportation of Kinshasa (STK) is created on September 23, 1968 which puts into circulation a 30-bus cartage completed in 1969 by a second cartage of 40 new buses. It operates 19 lines and has opened agencies within the country decline in 1979 and went bankrupt in 1982.

3) SOZACOM created in 1979 and goes bankrupt in 1982. It was a mixed and urban company with car cartage of 118 buses (Mwanza, 1997).

4) Zairian Transport Company (SOTRAZ) created in 1978 which operated only two (2) lines, but will disappear completely in 1982.

5) Zairian-Moroccan Transport Company (TRANZAM) created in 1989 with 160 Volvo buses. TRANZAM had 320 buses will disappear only in a few years before its fifth anniversary.

Table 1. Diachronic perspective of public transportation companies in the DRC.

\begin{tabular}{cccccc}
\hline No & Name & $\begin{array}{c}\text { Years of } \\
\text { creation }\end{array}$ & $\begin{array}{c}\text { Years of } \\
\text { decline }\end{array}$ & $\begin{array}{c}\text { Management } \\
\text { Type }\end{array}$ & Nature of activity \\
\hline 1 & TCL & 1947 & 1976 & Mixed & Urban and Picking up Staff \\
2 & STK & 1968 & 1982 & Public & Urban \\
3 & SOZACOM & 1979 & 1982 & Mixed & Urban and Picking up Staff \\
4 & SOTRAZ & 1979 & 1993 & Mixed & Urban, Regional and School \\
5 & TRANZAM & 1989 & 1992 & Mixed & Urban \\
6 & CITY-TRAIN & 1989 & 2013 & Public & Urban \\
7 & STUC & 2006 & 2012 & Public & Urban \\
\hline
\end{tabular}

Source: Summary of the documentary analysis (Mwanza, 1997; DRC-Office of Roads, 2001; Mutombo, 2008, Luboya, 2011) [1] [2] [39]. 
6) City-Train created in 1989 and having a park of 234 buses operated and works interspersed by words and rebirths and it has fallen permanently bankrupt since 2013 .

7) Society of Urban Transportation of the Congo (STUC) is the last company in disappearance, created in 2004, and set up in October 2006; it had a park of 243 buses. But to this day, this park is more made up of buses and minibuses broken down and downgraded and the company went bankrupt around 2012.

\subsection{Life Cycle of Public Transportation Companies in DR Congo According to the Duration and Types of the Life Cycles}

According the life cycle, the transit companies in DR Congo have lived in the long and medium term. Most of companies (71\%) lived long-term, from 14 to 29 years and $29 \%$ of companies lived in the medium term (Figure 1).

According to the stages, the public transportation companies in DR Congo have lived a complete cycle (57.14\%), incomplete cycle (14.29\%) and reincarnation cycle (28.57\%). Public Transportation in Leopoldville (TCL); Company of Transportation of Kinshasa (STK), SOZACOM and the Zairian Transport Company (SOTRAZ) have undergone a complete cycle. The Zairian-Moroccan Transportation Company (TRANZAM) lived the incomplete cycle and the CITY-TRAIN and the Society of Urban Transportation of the Congo (STUC) lived the cycle of death and reincarnation (Figure 2).

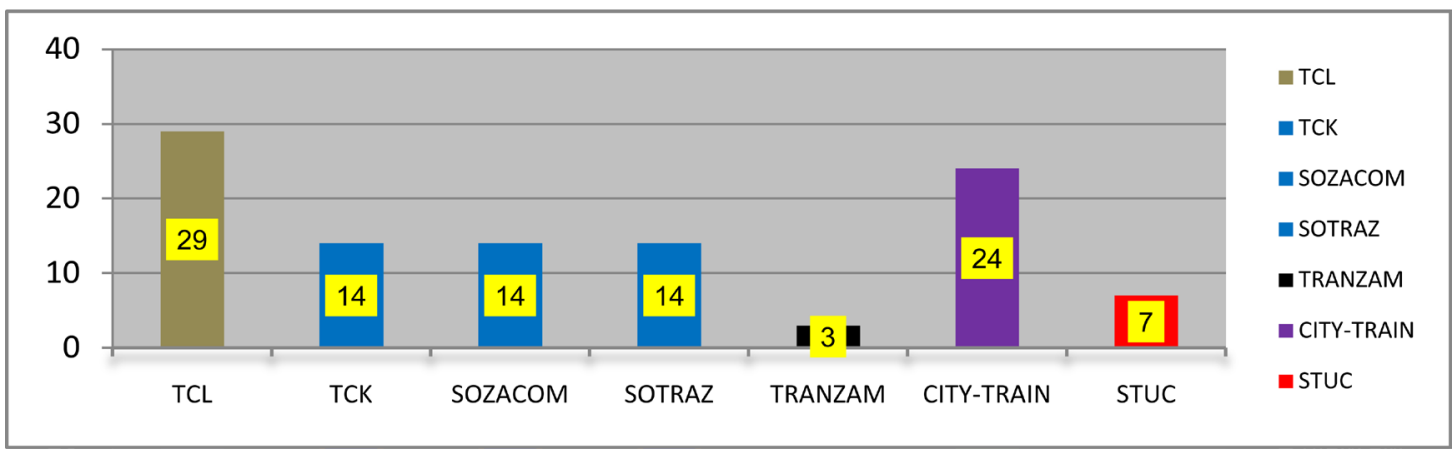

Source: Authors draw from Table 1 data.

Figure 1. Life cycle of public transportation companies in DR Congo by duration.

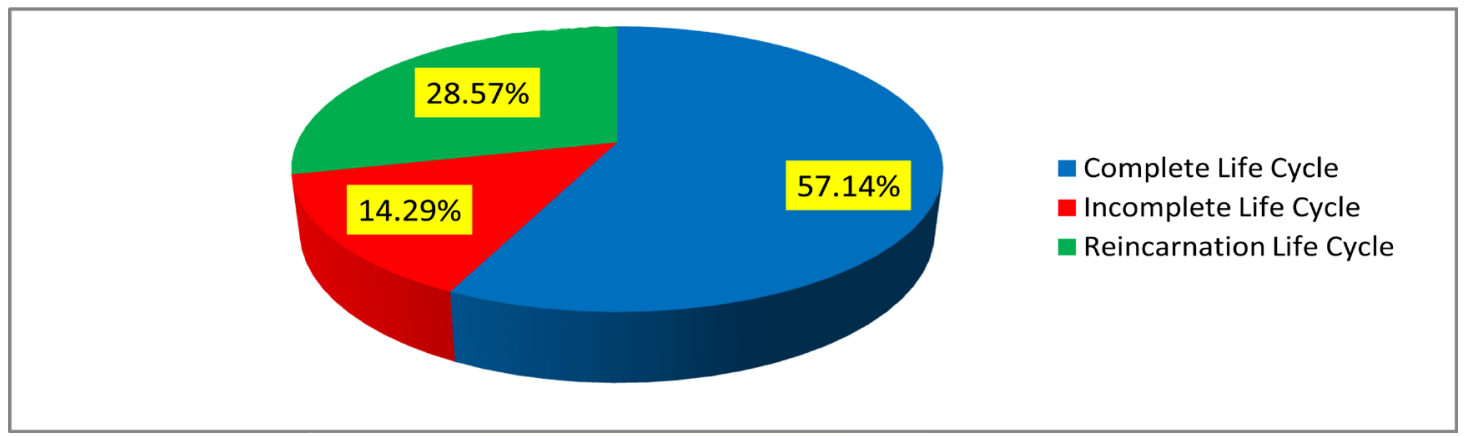

Source: Authors draw from interviews.

Figure 2. Life cycle of public transportation companies in DR Congo according cycle type. 


\subsection{Description of the Life Cycle Stages of Transportation Companies in the DRC according to the Synchronic Perspective Illustrated by STUC}

To illustrate the life cycle stages of public transportation companies in the DRC, the study uses the data from the Society of Urban Transportation of the Congo (STUC). The STUC is last public company went bankrupt after its failure in 2010 and its reincarnation in 2011 and then its death in 2012.

\section{1) Birth or Launch}

The Society of Urban Transportation of the Congo (STUC) was formally established by the Ministerial Decree of 13 August 2005 establishing the Commission for the monitoring of the operations of STUC Sarl. This ministerial decree was materialized in April 2005 when the memorandum of contract followed by the signing of the "Framework Agreement for the provision of buses, spare parts and technical assistance" was signed in May 2005 between the Government of the DRC and the Indian Company TATA Motor Limited.

The STUC was created in order to relaunch the public transportation sector in the Democratic Republic of the Congo. The STUC had to respond imperatively to the pressing demand of the authorities and to the legitimate satisfaction of the population of Kinshasa, to restore a public transportation system in failure in the DR Congo into organized common transportation services, to ensure a transportation of Quality to all Congolese.

In this phase, STUC had as the main operational goals: 1) the production of a quality and comforting public transportation service which was based in operational, specific and measurable terms and 2) the direction of the activities was oriented to production or maximum exploitation of network of common transportation.

The dominant group of Management Board was the DRC government delegates; delegates' agents of Ministry of Transportation and Communications Channels; Some STUC employees recruited and some Indian technicians. STUC production strategy was simple: operation of long lines linking large centers of concentration of population activity; its environmental influence was great with a nickname "Makola Ya Bana Ya Congo" (The foot of DRC people). The STUC structure and employees size were small and the whole organization reacted; its growth rate inconsistent and rising. The STUC did not have a detailed formal structure; its activities were not planned and its communication strategy was informal.

\section{2) Growth or Youth}

The STUC is a mixed-economy company with its proper structural structure. It required to the managers of different components to equip this company that had several shareholders with employees and formal management structure (the DRC governance with $96.3 \%$ of the financial contributions, Mrs Charles Lututa Ilongosi with $3 \%$ as well as seven shareholders with $0.7 \%$ ). These components of shareholders had two tendencies within the form of a modern homogeneous or- 
ganization.

In this phase, STUC operated only 4 lines dated February 20, 2006 with 10 buses; On June 23, 2006, it will operate with 40 buses. Already dated August 15, 2006, the company operated a park of 75 buses and 5 minibuses then on 2 October 2006 the start-up of 11 new buses. We also note that on 12 October of the same year, STUC arrived to operate 103 buses and 27 minibuses.

Before the end of the year 2006, i.e. on December 16, the number of operational buses increased from 103 to 113 buses and 22 minibuses. 3 buses were in maintenance state. It was in this phase of youth that the departmental structure and then the Divisions of the company were created. Because it was necessary not only to develop the structures by dividing the socio-economic role of each party but also to set up a unique managerial system responsible for the whole company. Remember that in this phase, the STUC had accelerated recruitment until reaching April 30, 2007 a total of 1413 employees with Vehicle Park of 234 buses.

This phase is also the phase during which STUC had maximized its daily, weekly, monthly or even yearly economic revenues. And STUC did exclusively and essentially resort to the recruitment of the transportation professionals of the former companies in disappearance. Its objectives were less operational, more general and in medium-term; its orientation of activities was oriented towards the marketing of new networks (lines) created. The dominant group was that of professional production managers. Therefore, it was in this phase that the desire and the genuine need for a simple, certain, effective information and management system was necessary.

\section{3) Maturity or Stabilization}

With regard the maturity phase, the STUC had reached this stage when it had assured the transportation market monopole of DRC, particularity in Kinshasa. In this phase, stucco succeeded in securing the monopoly of the public transportation sector in Kinshasa with the operation of 243 buses and minibus included. It operated more than 68 lines connecting the remote neighborhoods to the city center i.e. connecting the east of the city (Kinkole-Kingasani) to the West (Kinsuka) of the city via the Business Centre (Gombe). It has conquered to consolidate its mission and especially its market at a given time (period that goes from 2006, 2007 to 2008).

At maturity, STUC started to achieve objectives that are less operational and more general and in the long term. Establish an organizational structure and a computerized management system. Its direction was more in the finances, its structure had become formal and decentralized; its very formal communication; its size more awake and bigger. During this phase, the enterprise locked itself in its former glory of the past by the total absence of new initiatives. This lack of new strategies has led this company to decline due to several challenges and factors.

\section{4) Decline or Failure}

The situation of the decline started since the end of the year 2009. In January 
2010, the STUC had only 10 buses, minibuses included, and then around of July 2010, some of the STUC managers in particular the current directors of the Technical Division and the Operating Department attest to the momentary suspension of the Traditional activities and operations of buses and minibuses in urban lines and networks. Except the exploitation of some inter-urban networks (Bandundu and Bas Congo) and the rental networks (Ecole Lupio, Clinique Ngaliema, college Elykia and others) due the failure of many buses and minibuses broken down or even downgrading of others. The study also notes that, in this phase, the last group of 51 officers and employees were released on technical fire. Always in this phase, some elder employees of the STUC affirmed during the interviews that in July 2010, the STUC almost no longer existed. Some of them nuance as well as: "STUC was going through huge difficulties in all planes [...] In addition, a large number of staff had accumulated a few dozen months of non-payment of their salaries. And the others fired or withdrew themselves from the work".

\section{5) Death, Renaissance and Death}

In this phase, the study notes that the failed situation of STUC had not left the Congolese government indifferent. Remembering service that STUC offered to the Congolese population in general and those of Kinshasa particularly, the DRC Government was determined not to see the STUC disappear. The Government decided to sort out this company in failure of transportation services. The Central Executive intervened in the amount of US \$1 million around August 2010. Since that date, the STUC with the new Sanitation and Recovery Committee pointed by the Government rehabilitated some of its buses and minibuses hit with national colors on each side. The study notes that the expected result of this rehabilitation program is to achieve in the short term, a fleet of 70 operational buses whose average cost of rehabilitation is estimated to be approximately US $\$ 150,000$. Thus, in October 23, 2010, ten buses, including rehabilitated minibuses, were presented to the Minister of Transport and Communications, after a failure time of STUC activities.

During this period, the STUC reminded its agents on technical leave including the last group of 51 agents. STUC relaunched its activities and its common transportation operations in an express but unconventional manner. Around 2011, STUC operated 5 lines of urban networks and some lines of inter-urban networks with a park automobile valued at 58 buses rehabilitated for a total workforce of 235 workers including: 5 executive agents, 33 collaboration frameworks; 54 Control officers and 143 executing agents (drivers, controllers, receivers, mechanics and supervisors). Towards the end of the year 2013, the STUC fell into bankruptcy completely and definitively.

6) Quantitative analysis of life cycle of STUC

It observed from data on life-cycle stages that the life cycle of STUC can be classified into two categories:

According the stages, STUC lived five stages during 87 months (7 years and 3 
months): a) birth or launch from August 13, 2005 to May 20, 2006; b) growth or youth from 23 June 2006 to March 2007; c) maturity from 2 April 2007 to December 2009; d) decline or failure from January 2010 to early October 2010 and e) death, renaissance and death from October 23, 2010 to October 2012 (Figure 3).

Depending on the duration, the STUC lived longer in the phase maturity or stabilization: $37.93 \%$ of the duration of its life; followed by the phase of death, renaissance and death $(27.60 \%)$, then the same duration, $11.49 \%$ respectively for the phase of birth or launch; growth or youth and decline or failure (Figure 4).

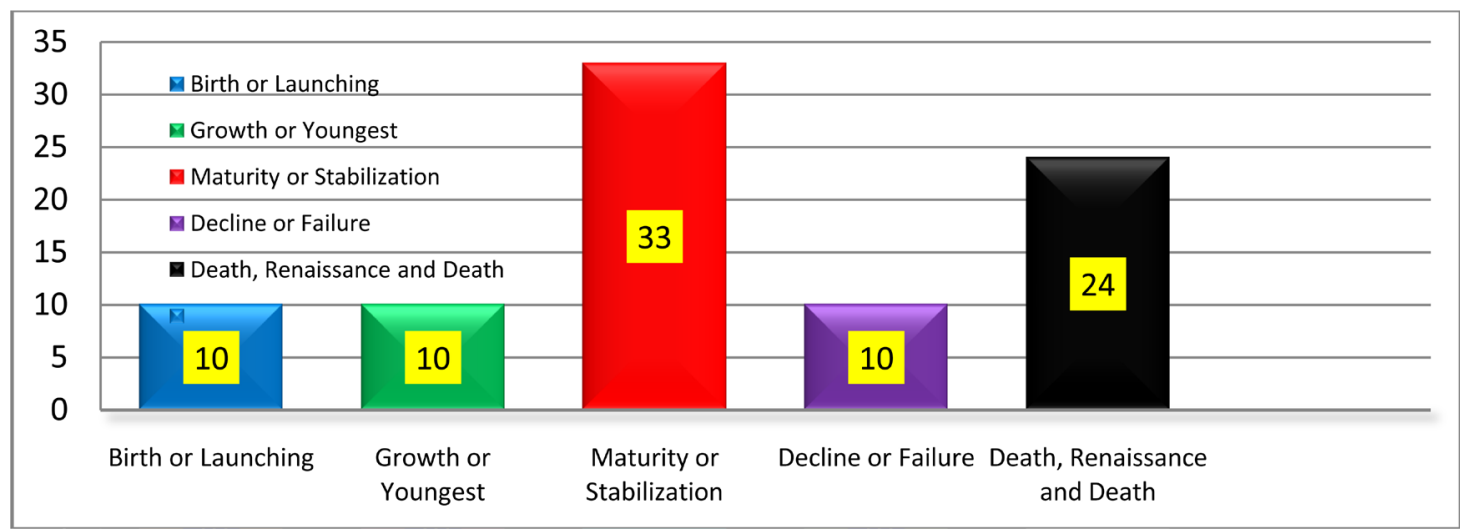

Source: Authors draw from interviews.

Figure 3. Life cycle of STUC in the perspective of phase.

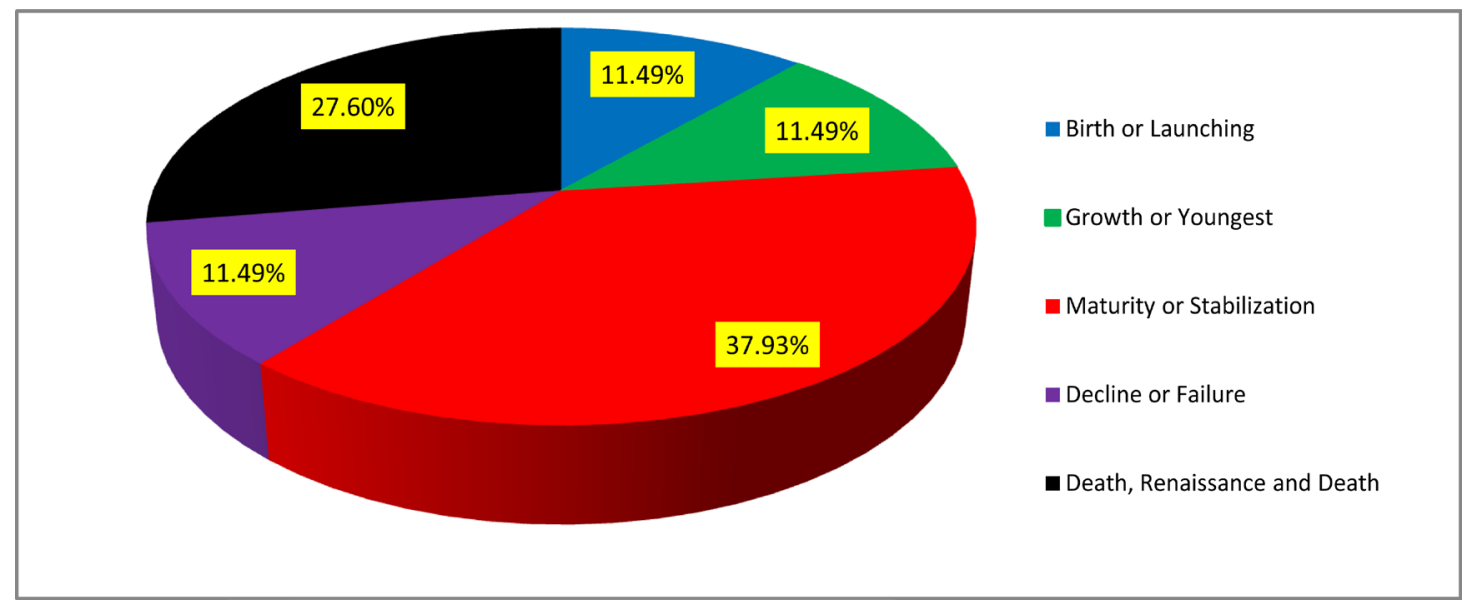

Source: Authors draw from interviews.

Figure 4. Life cycle of STUC in the perspective of duration of phase.

\section{Discussion}

The present study was carried out in the national environment particularly in the companies of transportation sector. For more than three decades, the transportation challenges have taken place in the DRC. The offer is less than demand and especially in big cities. The study found that transportation companies in the DRC eventually fall into bankruptcy. The study aims at tracing, analyzing and 
describing the life cycles of these public companies according to the duration, types and stages or phases.

The findings showed that eight large public transportation companies have been created between years 40 and actually in the DRC. Most of these companies (7 out of 8 , or $87.5 \%$ ) went bankrupt and lived through life cycles during their lives. Several theoretical and empirical studies (Luboya, 2018; Luboya et al., 2017; Hatch, 1997; Lakoff and Johnson, 1980; Hersey et al., 1972; Frois, 1997; Quinn and Cameron, 1983; Luboya, 2011, 2014) [1] [21] [22] [23] [25] [26] [27] [28] have pointed out that organizations have the opportunity to live several stages of life cycles. This study showed that most public transportation company of DRC lived the life cycle in long-term. These companies lived in the period when the DRC economic situation was moderately stable. They have experienced a complete life cycle. The maturity is the longest phase in their life cycle time in the illustrated case of one of these companies. The other companies that have been created in an uncertain economic situation of DRC have almost lived in the short term with two types of life cycle either incomplete or reincarnation (death, Renaissance and death). In other words, the more the economy situation of country is moderately stable, national company tends to resist longer. Otherwise the uncertain economic situation makes the life cycle of national transportation companies vulnerable. After decade $90 \mathrm{~s}$, the DR Congo loved the economic crisis and its economic situation is remaining no appreciable. Luboya (2018) [21] highlighted similar findings on private schools experiencing the bankruptcy or failure in the DRC. The majority of the private schools analyzed experienced the complete life cycle and in long-term.

\section{Conclusions}

The finding of this study highlighted the life cycles of public transportation companies in DR Congo in a diachronic and synchronic analysis. The finding of study showed that the DRC public transportation companies lived in long and medium terms through three possible cycles, including complete, incomplete and reincarnation or between death-renaissance-death. In the experience of their stages, these companies spend their longtime of life cycle in the phase of maturity or stabilization and other phases are lived no longer. Although all of these companies went bankrupt, their resistance during their life cycle depends to the national economic situations and other possible factors which must to be analyzed. The further study should explore the management and technical factors as well as occasional and structural factors.

Theoretically and methodologically, this study is a tool for life cycle analysis according to the diachronic and synchronic perspective. It shows the life cycles of the national enterprises disappointed or bankruptcy in the transportation area. The indicators of duration, types and steps have been clarified. The findings of the study can help in the development of analysis tool and life cycle management of companies during the period of their lives and after the bank- 
ruptcy.

Politically and economically, decision-making authorities or policy makers and economic operators have benchmarks capable of guiding their decision in regulating this sector and in all attempts to invest in transportation companies in the DRC.

However, the study was interested in DRC public transportation companies and its findings are valid only for the public sector. It is impossible to generalize these conclusions in the private sector. The further studies must be carried out in the companies of private sector. This area controls a large share of the public transportation market in DR Congo. The studies must also be directed towards analysis of the explanatory factors of failure cases and bankruptcies of public and private transportation companies.

\section{References}

[1] Luboya, T.C. (2011) Explanatory Factors of the Company of Urban Transportation of the Congo. National Pedagogical University, License Thesis, Kinshasa.

[2] Mwanza, M. (1997) Le Transportation Urbain à Kinshasa: Un nœud gardien. Le Harmattan, Paris.

[3] Kabambu, M. (2004-2005) The Inadequation between the Supply and Demand for Common Transportation of Public Enterprises: Case of the City of Kinshasa of 1984-2004. University of Kinshasa, Bachelor Thesis, Kinshasa.

[4] Mputu, M. (2004-2005) Problematic of Public Transportation Facing the Population Growth in the City of Kinshasa. University of Kinshasa, Bachelor Thesis, Kinshasa.

[5] Mutumbo, M.J.-C. (2007-2008) The Impact of the Kinshasa Population Explosion on Urban Transportation: Case of the Neighborhoods Binza Pigeon and Djelo Binza in the Commune of Ngaliema. National Pedagogical University, Bachelor Thesis, Kinshasa.

[6] Blazy, R. and Comber, J. (1998) Défaillance des Entreprises. PUF, Paris.

[7] Cameron, K. (1986) Effectiveness as Paradox: Consensus and Conflict in Conceptions of Organizational Effectiveness. Management Science, 32, 539-553. https://doi.org/10.1287/mnsc.32.5.539

[8] Miller. (1992) Environmental Fit versus Internal Fit. Organization Science, 3, 159-178. https://doi.org/10.1287/orsc.3.2.159

[9] Tushman, M.L., Newman, W.H. and Romanelli, E. (1986) Convergence and Upheaval: Managing the Unsteady Pace of Organizational Evolution. California Management Review, 29, 29-44. https://doi.org/10.2307/41165225

[10] Crutzen, N. and Van Caillie, D. (2007) The Business Failure Process: Towards an Integrative Model of the Literature. EIASM Workshop on Default Risk and Financial Distress, Rennes (France), 13-14 September.

[11] Argenti, J. (1976) Corporate Collapse: The Causes and Symptoms. Holsted Press, McGraw-Hill, London.

[12] D’Aveni, R. (1989) The Aftermath of Organizational Decline: A Longitudinal Study of the Strategic and Managerial Characteristics of Declining Firms. Academy of Management Journal, 32, 577-605.

[13] Laitinen, E.K. (1991) Financial Ratios and Different Failure Processes. Journal of 
Business, Finance and Accounting, 18, 649-673. https://doi.org/10.1111/j.1468-5957.1991.tb00231.x

[14] Beaver, W. (1966) Financial Ratios as Predictors of Failure, Empirical Research in Accounting: Selected Studies. Supplement to the Journal of Accounting Research, 6 , 71-87. https://doi.org/10.2307/2490171

[15] Zavgren, C. (1983) The Prediction of Corporate Failure: The State of the Art. Journal of Accounting Literature.

[16] Van Wymeersch, C. and Wolfs, A. (1996) La trajectoire de faillite des entreprises: Une analyse chronologique sur base des comptes annuels. Cahiers de la Faculté des Sciences Economiques et Sociales, 172.

[17] Balcaen, S. and Ooghe, H. (2006) The Exit Path of Failing Firms: Which Factors Determine the Time to Exit? Working Paper Series, Vlerick Leuven Gent Management School.

[18] Dimitras, A., Zanakis, S. and Zopoudinis, C. (1996) A Survey of Business Failures with an Emphasis on Failure Prediction Methods and Industrial Applications. European Journal of Operational Research, 90, 487-513. https://doi.org/10.1016/0377-2217(95)00070-4

[19] Morris, R. (1997) Early Warning Indicators of Corporate Failure: A Critical Review of Previous Research and Further Empirical Evidence. Ashgate Publishing Ltd., 421.

[20] Crutzen, N. and Van Caillie, D. (2007) The Prevention of Business Failure: A State of the Art. Accounting History.

[21] Luboya, T.C. (2018) Life Cycle of Private Schools Experiencing Failure in Democratic Republic of Congo. A Mixed Method and Triangulation Study. Scholars' Press.

https://www.scholars-press.com/catalog/details/store/pt/book/978-620-2-30777-2/li fe-cycle-of-private-schools-experiencing-failure-in-dr-congo?search=978-620-2-307 $\underline{77-2}$

[22] Hatch, J.M. (1997) La théorie des organisations: Perspectives modernes, symboliques et postmodernes. Oxford University Press, Oxford.

[23] Hersey, P., Kenneth, K. and Blanchard, H. (1972) Management of Organizational Behavior: Utilizing Human Resources. Prentice-Halls, Englewood Cliffs.

[24] Adizez et Ichak (1988) Life Cycle Organisationnels. Prentice Hall, Englewood Cliffs. In: Corneille, L.T., Ed., Analysis of the Explanatory Factors of the Bankruptcy of Schools Using the Balanced Unifying Model, DEA Thesis, National Pedagogical University, Kinshasa.

[25] Quinn, R.E. and Cameron, K. (1983) Organisation: Cycles de vie et certains critères de l'efficacité. West Publishing, Eagan.

[26] Frois, P. (1997) Entreprise et écologie. Le Harmattan, Paris.

[27] Lakoff, G. and Johnson, M. (1980) Metaphors We Live by. University of Chicago Press, Chicago.

[28] Luboya, T.C., Batekele, L. and Yawidi, J. (2017) Life Cycle of Private Schools Experiencing Failure in Democratic Republic of Congo. Open Journal of Social Sciences, 5, 318-342.

http://www.scirp.org/Journal/PaperInformation.aspx?PaperID=80085

[29] Berg, B.L. (2009) Qualitative Research Methods. Allyn \& Bacon, New York.

[30] Punch, K.F. (2005) Introduction to Social Research: Quantitative and Qualitative Approaches. Sage Publications, London.

[31] Creswell, J.W. (2007) Qualitative Inquiry and Research Design: Choosing among 
Five Approaches. SAGE Publications, London.

[32] Pochet, B., Chevillotte, S. and Noel (2005) Méthodologie documentaire: Rechercher, consulter, rédiger à l'heure d'internet. De Boeck, Bruxelles.

[33] Bashwtitz, B., Antonia, M., De Ketele, J.-M. and De Godelet, E. (2010) Comment me documenter? Formateurs, enseignants, étudiants. De Boeck, Bruxelles.

[34] McNamara, C. (1999) General Guidelines for Conducting Interviews. Sage, Minnesota.

[35] Chilisa, B. and Preece, J. (2005) Research Methods for Adult Educators in Africa. Pearson Education, Cape Town.

[36] Kvale, S. (1996) Interviews an Introduction to Qualitative Research Interviewing. Sage, London.

[37] Bardin, L. (1993) Analysis of Content. PUF, Paris.

[38] Baumard, et al. (2003) La collecte des données et pratique de leurs sources. Dunod, Paris.

[39] DRC-Ministère de Transport, Office de Route (2001) Rapport d'étude. Ministère de Transportation, Kinshasa. 